\title{
Degradation of nitroaromatic compounds: a novel approach using iron from laterite soil
}

\author{
A. S. Amritha ${ }^{1}(1) \cdot$ B. Manu ${ }^{1}$
}

Received: 5 June 2016 / Accepted: 31 July 2018 / Published online: 7 August 2018

(c) The Author(s) 2018

\begin{abstract}
The Fenton's oxidation process has been found to be a simple and economical method for the treatment of nitroaromatic compounds in water. In the present study, the iron extracted from the laterite soil was used as a catalyst and optimization of $\mathrm{pH}$, hydrogen peroxide concentration and iron concentration was studied for different initial concentrations of 2-nitroaniline (2-NA), 3-nitroaniline (3-NA) and 4-nitroaniline (4-NA). The optimum $\mathrm{pH}$ obtained was 2.5 for 2-NA and 3-NA and 3 for 4-NA. The maximum removal efficiency obtained was $85.3 \%, 84.3 \%$ and $98.7 \%$ for $0.5 \mathrm{mM}$ initial concentration at a hydrogen peroxide concentration of $3.5 \mathrm{mM}, 4.5 \mathrm{mM}$ and $5 \mathrm{mM}$ for 2-NA, 3-NA and 4-NA, respectively, with a constant iron concentration of $0.05 \mathrm{mM}$.
\end{abstract}

Keywords Nitroaromatic compounds · Degradation · Fenton's oxidation · Iron from laterite as a catalyst

\section{Introduction}

In the Indian economy, an industry plays an important role. Dye manufacturing industries, pharmaceuticals, pesticides, etc., represent the strong and fast-growing sector of the Indian industry. The untreated wastewater from industries, such as dyes, pharmaceuticals, pesticides, antiseptic agents, medicines for pharmaceutical and poultry synthesis, gums, distillery, dye intermediates and printing, is the major contributors that cause damage to the water quality. The untreated wastewater disposals from these industries affect the quality of water and may have health issues such as blood, enzyme and nerve damage with cyanosis and the danger of suffocation. These industries use different commercial products and chemicals such as aniline and its derivatives, dyes and $\mathrm{pH}$ regulators.

Aniline has the general ability to inhibit enzyme activity, and hence, this has been listed as a probable human carcinogen by US Environmental Protection Agency (Dvorak et al. 2014). The aromatic amines such as aniline derivatives have widespread applications as dye intermediates, and most commonly used derivatives are 2-nitroaniline, 3-nitroaniline

A. S. Amritha

amritha86@gmail.com

1 Department of Civil Engineering, NITK, Surathkal, Mangaluru, Karnataka 575025, India and 4-nitroaniline (Sun et al. 2007). These aniline derivatives are used in the manufacture of different types of dyes such as acetate dyes, direct dyes and disperse dyes. These dyes are manufactured in China and India. If $1000 \mathrm{mg} / \mathrm{L}$ of dye is present in a dye bath (Manu and Chaudhari 2002) and about $50 \%$ is lost into effluent (Khan et al. 2004), the concentration of nitroanilines in effluent may exceed $300 \mathrm{mg} / \mathrm{L}$ since these are used as an intermediate.

The discharge of the untreated wastewater containing the aniline derivatives is harmful to the water bodies (Sun et al. 2008). Hence, the removal of these aniline derivatives from the industrial wastewater is very important to reduce the pollution of the water bodies. The physical, biological and chemicals methods are available for the removal of these aniline derivatives. The biological treatment methods are not efficient for the removal of these aniline derivatives even though these methods are economical and also nitro group present in the aromatic ring enhances the stability to these aniline derivatives. Among the chemical treatment methods, for the removal of the removal of these aniline derivatives, the advanced oxidation processes (AOPs) are the most promising methods (Sun et al. 2008). The Fenton's oxidation process is another promising oxidation process for effective removal of the non-biodegradable pollutants (Neyen and Baeyens 2003). In the Fenton's oxidation process, complex organic compounds are broken down in the form of carbon dioxide and water (Wang et al. 2016). 
Conventionally in the Fenton's process, iron which acts as a catalyst is supplied using iron sulfate which adds to the cost of the process. Hence, there is a need to develop an economical process for the removal of the aniline derivatives from contaminated wastewater. In the present study, a low-cost naturally available material such as laterite which can supply iron as a catalyst can enhance the availability of hydroxyl radical. An attempt has been made for the degradation of the aniline derivatives using iron extracted from laterite as a catalyst to enhance the generation of hydroxyl radical.

\section{Materials and methods}

\section{Chemicals}

2-Nitroaniline, 3-nitroaniline and 4-nitroaniline were purchased from Himedia. Iron (II) sulfate heptahydrate $\left(\mathrm{FeSO}_{4} \cdot 7 \mathrm{H}_{2} \mathrm{O}\right)$, hydrogen peroxide $(50 \% \mathrm{w} / \mathrm{w})$, hydrochloric acid $(\mathrm{HCl})$, sodium hydroxide $(\mathrm{NaOH})$, sulfuric acid $\left(\mathrm{H}_{2} \mathrm{SO}_{4}\right)$ were procured from Merck India. The reagents used are of analytical grade and used without purification.

\section{Experimental methods}

The 2-NA, 3-NA and 4-NA stock solution in distilled water was prepared. The batch experiments were conducted in a 2000-mL Erlenmeyer flask at ambient temperature. The $\mathrm{pH}$ was adjusted using $0.1 \mathrm{mM}$ of $\mathrm{H}_{2} \mathrm{SO}_{4}$ and $0.1 \mathrm{mM}$ of $\mathrm{NaOH}$. The iron extraction from laterite was carried out as per the procedure outlined by Olanipekun (2000). The required dosage of the iron extracted from laterite soil was added to the solution to start the reaction, and then, the hydrogen peroxide was added. After the solution was mixed continuously at $200 \mathrm{rpm}$ using magnetic stirrer, the samples were drawn for analysis after the reaction time and filtered using $0.45-\mu \mathrm{m}$ Millipore filter membrane for further analysis.

\section{Analytical methods}

A standard solution of 2-nitroaniline, 3-nitroaniline and 4-nitroaniline was prepared using $5 \mathrm{mM}$ stock solution. The absorbance peak was recorded from 200 to $500 \mathrm{~nm}$ using UV-Vis spectrophotometer (Systronics-2201). The $\mathrm{pH}$ was measured using the digital $\mathrm{pH}$ meter (Lovibond). The COD, residual hydrogen peroxide, iron concentrations were measured as procedure outlined in the standard methods for the examination of water and wastewater (Eaton et al. 2005). The HPLC analysis was carried out using HPLC (Agilent Binary LC) which has an RP ZORBAX C18 silica column, with diode array detector (DAD) to confirm the results.

\section{Results and discussion}

\section{Effect of pH}

The present study is carried out to test the potential of iron extracted from laterite to replace the $\mathrm{FeSO}_{4}$ normally used in the Fenton's process and also to optimize the process conditions, viz. $\mathrm{pH}$, hydrogen peroxide and iron concentration.

The $\mathrm{pH}$ value influences the hydroxyl radical generation which increases the oxidation efficiency. The experiments were conducted in the range of 2-4 to determine the optimum $\mathrm{pH}$. The initial 2-NA, 3-NA and 4-NA concentration was $0.5 \mathrm{mM}$. The other operating parameters were $\mathrm{H}_{2} \mathrm{O}_{2}$ : $3.5 \mathrm{mM}$ and Fe: $0.5 \mathrm{mM}$.

Figure 1 shows the effect of $\mathrm{pH}$ on 2-NA, 3-NA and 4-NA removal efficiency. It can be observed from the figure that the removal efficiency increases initially, and thereafter, the removal of nitroaromatic compounds decreases at higher $\mathrm{pH}$ value.

The optimum $\mathrm{pH}$ of 2.5 was obtained for $2-\mathrm{NA}$ and 3-NA, and for 4-NA, it was 3. The maximum removal efficiency for 2-NA, 3-NA and 4-NA at optimum $\mathrm{pH}$ values is $89.1 \%, 86.5 \%$ and $88.2 \%$. Maximum removal efficiency at the optimum $\mathrm{pH}$, may be due to the formation of $\mathrm{Fe}(\mathrm{OH})^{+}$which is more active than the $\mathrm{Fe}^{2+}$ in Fenton's oxidation process (Badaway and Ali 2006). When $\mathrm{pH}$ is less than the optimum $\mathrm{pH}$, the reaction between the $\mathrm{H}_{2} \mathrm{O}_{2}$ and $\mathrm{Fe}^{2+}$ is affected so to reduce the formation of the hydroxyl radical and the formation of water by reaction between $\mathrm{OH}$ radical with $\mathrm{H}^{+}$ions (Lucas and Peres 2006). When the $\mathrm{pH}$ is more than the optimum $\mathrm{pH}$, removal efficiency decreases due to the decrease in the oxidation efficiency and may be due to autodegradation of $\mathrm{H}_{2} \mathrm{O}_{2}$ which will affect the formation of $\mathrm{OH}$ radicals (Badaway and Ali 2006).

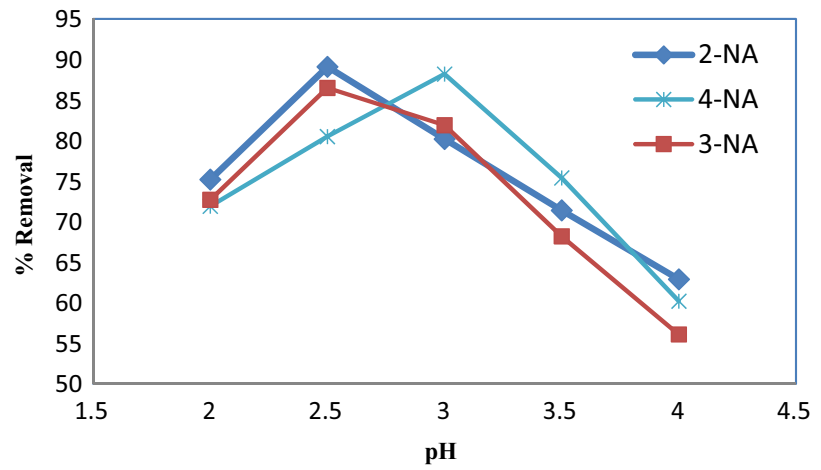

Fig. 1 Effect of $\mathrm{pH}$ on removal of 2-NA, 3-NA and 4-NA 


\section{Effect of $\mathrm{H}_{2} \mathrm{O}_{2}$ concentration}

The effects of the concentration of peroxide and iron on the removal of chosen nitroaromatic compounds are studied, and the results are presented as below. The peroxide concentration was varied in the range of $2-22 \mathrm{mM}$ for 2-NA, 3-25 mM for 3-NA and 5-27.5 mM for 4-NA, and similarly iron concentration was also varied from 0.025 to $0.275 \mathrm{mM}$ concentration. The concentration of the nitroaromatic compounds was varied from 0.5 to $2.5 \mathrm{mM}$. Table 1 presents removal efficiency of the chosen compounds and COD removal efficiency at different optimum peroxide and iron concentrations for the different initial concentrations of the chosen compounds.

The maximum removal efficiency of $89.15 \%$ and COD removal of $73 \%$ were obtained for 2-NA concentration at hydrogen peroxide concentration of $3.5 \mathrm{mM}$ and $\mathrm{Fe}$ concentration of $0.05 \mathrm{mM}$. The maximum removal efficiency of 3-NA of $84.3 \%$ and COD removal were $68.5 \%$ when the hydrogen peroxide concentration was $4.5 \mathrm{mM}$ and iron concentration of $0.05 \mathrm{mM}$. The maximum 4-NA removal of $98.7 \%$ and COD removal of $84.7 \%$ were obtained at

Table 1 Maximum removal efficiencies and optimum dosages of 2-NA, 3-NA and 4-NA at different initial concentrations

\begin{tabular}{|c|c|c|c|}
\hline Initial concentration & 2-NA & $3-\mathrm{NA}$ & 4-NA \\
\hline \multicolumn{4}{|l|}{$0.5 \mathrm{mM}$} \\
\hline$\%$ Removal & 85.3 & 84.3 & 98.7 \\
\hline$\%$ COD removal & 69.9 & 68.5 & 84.7 \\
\hline Optimum $\mathrm{H}_{2} \mathrm{O}_{2}(\mathrm{mM})$ & 3.5 & 4.5 & 5.0 \\
\hline Optimum iron (mM) & 0.05 & 0.05 & 0.05 \\
\hline \multicolumn{4}{|l|}{$1 \mathrm{mM}$} \\
\hline$\%$ Removal & 82.5 & 82.5 & 96.1 \\
\hline$\%$ COD removal & 66.4 & 61.5 & 80.7 \\
\hline Optimum $\mathrm{H}_{2} \mathrm{O}_{2}(\mathrm{mM})$ & 7.5 & 9.5 & 10.5 \\
\hline Optimum iron (mM) & 0.1 & 0.1 & 0.1 \\
\hline \multicolumn{4}{|l|}{$1.5 \mathrm{mM}$} \\
\hline \%emoval & 81.7 & 80.3 & 94.7 \\
\hline$\%$ COD removal & 60.3 & 59.1 & 76.5 \\
\hline Optimum $\mathrm{H}_{2} \mathrm{O}_{2}(\mathrm{mM})$ & 12 & 14.5 & 16 \\
\hline Optimum iron (mM) & 0.15 & 0.15 & 0.15 \\
\hline \multicolumn{4}{|l|}{$2 \mathrm{mM}$} \\
\hline$\%$ Removal & 78.5 & 75.2 & 91.5 \\
\hline$\%$ COD removal & 58.2 & 55.9 & 75.3 \\
\hline Optimum $\mathrm{H}_{2} \mathrm{O}_{2}(\mathrm{mM})$ & 16 & 19.5 & 21.5 \\
\hline Optimum iron (mM) & 0.2 & 0.2 & 0.2 \\
\hline \multicolumn{4}{|l|}{$2.5 \mathrm{mM}$} \\
\hline \%Removal & 74.7 & 71.6 & 90.5 \\
\hline$\%$ COD removal & 56.2 & 52.2 & 72.8 \\
\hline Optimum $\mathrm{H}_{2} \mathrm{O}_{2}(\mathrm{mM})$ & 21 & 24.5 & 27 \\
\hline Optimum iron (mM) & 0.25 & 0.25 & 0.25 \\
\hline
\end{tabular}

hydrogen peroxide concentration of $5 \mathrm{mM}$ and at an iron concentration of $0.05 \mathrm{mM}$. It can be further inferred that the maximum removal efficiency of the chosen compounds occurred at the lowest chosen concentration of $0.5 \mathrm{mM}$.

Hydrogen peroxide plays an important role in Fenton's oxidation. It was observed that increase in hydrogen peroxide concentration increased pollutant degradation. This trend is observed till hydrogen peroxide reaches a critical concentration; any further increase in the hydrogen peroxide concentration decreases the degradation. This may be because the production of hydroxyl radicals increases with the increase in the hydrogen peroxide concentration, and hence, there is an increase in the removal efficiency (Yilmaz et al. 2010). However, a further increase in the hydrogen peroxide concentration results in scavenging of the $\mathrm{OH}$ ion by hydrogen peroxide and the incremental generation of $\mathrm{OOH}$ radical which also consumes $\mathrm{OH}$ radical; hence, the removal efficiency decreases (Walling and Kato 1971; Kang et al. 2002; Sun et al. 2007).

\section{Effect of iron concentration}

In order to find out the economical method for the degradation of 2-NA, 3-NA and 4-NA, the studies were carried out using the iron extracted from the locally available laterite soil. It was seen that the laterite extracted iron can also be used as a catalyst to enhance the hydroxyl radical generation. The optimum iron dosages were found out by varying the iron concentration from 0.025 to $0.275 \mathrm{mM}$ for 2-NA, 3-NA and 4-NA, and the optimum dosages obtained for varying concentrations are shown in Table 1.

The optimum iron concentration increases with the initial concentration of the pollutant concentration. For $0.5 \mathrm{mM}$ of 2-NA concentration, the optimum iron concentration obtained was $0.05 \mathrm{mM}$, whereas for $1,1.5,2$ and $2.5 \mathrm{mM}$, the optimum iron concentration obtained was $0.1,0.15,0.2$ and $0.25 \mathrm{mM}$, respectively. Similar trends were obtained for 3-NA and 4-NA. Iron was used as a catalyst to initiate the degradation by hydrogen peroxide. As the concentration of the iron increases, generation of $\mathrm{OH}$ radical increases which increases the degradation of the pollutant. At higher concentration of iron, the removal efficiency decreased, and it may be due to the ferrous ion inhibition (Manu and Mahamood 2011). Low concentrations of iron were used in the present study, proving their sufficiency to produce required quantity of $\mathrm{OH}$ radical to obtain the maximum degradation.

\section{Effect of initial concentration}

The effect of initial concentration on Fenton's oxidation process was studied by varying the initial concentration of the pollutant concentration on all the model compounds selected. The removal of chosen model compounds and

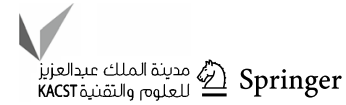




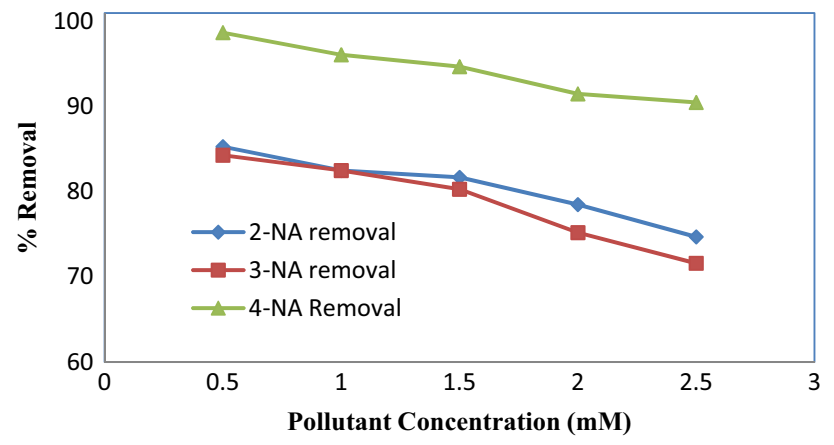

Fig. 2 Effect of initial concentration on removal of 2-NA, 3-NA and 4-NA

COD removal efficiency decreased with the increase in the initial concentration of the chosen model compounds. Table 1 and Fig. 2 present the results of the above study with respect to the decrease in the removal efficiency of the pollutant concentration.

This may be due to fact that the requirement of $\mathrm{OH}$ radical increases with the increase in the concentration, and since the availability of the $\mathrm{OH}$ radical increases is lesser, the removal efficiency decreases with the increases in the initial concentration (Sun et al. 2008) and the COD removal efficiency decreased at higher concentration may be because of the formation of the intermediates during Fenton's oxidation which traps $\mathrm{OH}$ radicals (Manu and Mahamood 2011).

The 4-NA has obtained maximum removal efficiency of $98.7 \%$ as compared to $85.3 \%$ of $2-\mathrm{NA}$ and $84.3 \%$ of 3 -NA. This may be due to the fact that anilines are ortho- and paradirecting groups, and steric hindrance is produced by aniline and nitro groups when the nitro group is in ortho position so degradation is difficult as compared to 4-NA. Hence, the 4-NA has obtained maximum removal efficiency than 2-NA and 3-NA (Ahluwalia 2010).

\section{Conclusions}

The present study has established that the degradation of the aniline derivatives (2-NA, 3-NA and 4-NA) depends on the $\mathrm{pH}$, hydrogen peroxide, iron and initial concentration. The optimum $\mathrm{pH}$ obtained during Fenton's oxidation was in acidic range, i.e., 2.5 and 3. The optimum hydrogen peroxide concentration obtained was $3.5-5 \mathrm{mM}$, and optimum iron concentration was $0.05 \mathrm{mM}$ to obtain the maximum removal efficiency. It has also been proved that the iron extracted from the laterite can also be used as a catalyst in Fenton's oxidation process which ultimately reduces the cost of the oxidation process.
Open Access This article is distributed under the terms of the Creative Commons Attribution 4.0 International License (http://creativeco mmons.org/licenses/by/4.0/), which permits unrestricted use, distribution, and reproduction in any medium, provided you give appropriate credit to the original author(s) and the source, provide a link to the Creative Commons license, and indicate if changes were made.

\section{References}

Ahluwalia VK (2010) Organic reaction mechanism. Narosa Publishing House Pvt Ltd, New Delhi

Badaway MI, Ali MEM (2006) Fenton peroxidation and coagulation processes for the treatment of combined industrial \& domestic wastewater. J Hazard Mater 136:961-966

Dvorak L, Lederer T, Jirku V, Masak J, Noval L (2014) Removal of aniline, cyanides and diphenylguanidine from industrial wastewater using full scale moving bed biofilm reactor. Process Biochem 49:102-109

Eaton AD, Clesceri LS, Greenberg AE, Franson MAH (2005) Standard methods for the examination of water and wastewater. American Public Health Association. American Water Works Association \& Water Environment Federation, Washington, DC, USA

Kang YW, Lee DS, Yoon J (2002) Kinetic modelling of Fenton oxidation of phenol \& monochlorophenols. Chemosphere 47:915-924

Khan TA, Sing VV, Kumar D (2004) Removal of some basic dyes from artificial textile wastewater by adsorption on Akash Kinari Coal. J Sci Ind Res 63(4):355-364

Lucas MS, Peres JA (2006) Decolourization of azo dye Reactive Black 5 by Fenton and photo fenton oxidation. Dyes Pigments 71:236-244

Manu B, Chaudhari S (2002) Anaerobic decolourization of simulated textile wastewater containing azo dyes. Bioresour Technol $82: 225-231$

Manu B, Mahamood S (2011) Enhanced degradation of paracetamol by UV-C supported photo-Fenton process over Fenton oxidation. Water Sci Technol 64(12):2433-2438

Neyen E, Baeyens J (2003) A review of classic Fenton's peroxidation as an advanced oxidation technique. J Hazard Mater B98:33-50

Olanipekun EO (2000) Kinetics of leaching laterite. Int J Miner Process 60:9-14

Sun HJ, Sun PS, Fan HM, Guo QH, Qiao PL, Sun XR (2007) A kinetic study on the degradation of p-nitroaniline by Fenton oxidation process. J Hazard Mater 148:172-177

Sun HJ, Sun PS, Fan HM, Guo QH, Lee FY, Sun XR (2008) Oxidative decomposition of p-nitroaniline in water by solar photo-Fenton advanced oxidation process. J Hazard Mater 153:187-193

Walling C, Kato S (1971) The oxidation of alcohols by Fenton's reagent: the effect of copper ion. J Am Chem Soc 93:4275-4281

Wang N, Zheng T, Zhang G, Wang P (2016) Review on Fenton-like processes for organic wastewater treatment. J Environ Chem Eng 4:762-787

Yilmaz T, Aygun A, Nas B (2010) Removal of COD and colour from young municipal landfill leachate by Fenton process. Environ Technol 31(14):1635-1640

Publisher's Note Springer Nature remains neutral with regard to jurisdictional claims in published maps and institutional affiliations. 